\title{
Different Arenas, Different Attitudes: Partisan Inconsistency in the Canadian Federal System
}

\author{
Harold D. Clarke, University of North Texas \\ Marianne C. Stewart, University of Texas at Dallas \\ with the assistance of \\ Alan Acock, Oregon State University \\ Suzanne L. Parker, Florida State University
}

Party identification occupies a prominent place in contemporary theory and empirical research. Although its dimensions, sources, and implications for political choice have received considerable attention, the effect of political-institutional contexts on partisan attachments remains largely unexplored. We examine the patterns of such attachments in a system with differing arenas of citizen participation, government responsiveness, and political parties at the national and subnational levels. We suggest that a confluence of long- and short-term forces operates to influence partisan attitudes at both levels of government, and that these attitudes, net of other factors, are important determinants of public issue concems, leader evaluations, and electoral choice. The correlates and consequences of partisan inconsistency in contemporary Canada are assessed using survey data from a series of studies conducted during the past two decades.

\section{The Phenomenon of Partisan Inconsistency}

The conceptualization of party identification is central to social-psychological and rational-choice theories of political behavior. According to a socialpsychological conception, party identification is a long-term, affective attachment (e.g., Campbell et al. 1960), whereas a rational-choice definition presents party identification as a potentially short-term, evaluative attitude, or "a running tally" of party performance judgements (e.g., Fiorina 1981). Although these alternative specifications have been a major issue in unresolved controversies over the utility of each theory, both theories offer potential explanations for the development of partisan attitudes in a polity characterized by differentiated contexts of political action.

Our general expectation is that a federal system, particularly one involving the operation of centrifugal forces, is an important source of contextual variation in the development of differing party identifications at the two levels of government. In formal terms, federal systems divide government functions to encourage citizen involvement and public accountability (Beam, Conlan and Walker 1983, 253-56). In practice during the post-World War II era, national and subnational governments have shared custody but each also has exercised primary authority 
over important policy areas. Equally significant, a federal system may increase the number of arenas in which inter-party conflict occurs, and thereby reinforce possible disparities in national and subnational party systems. In this regard, parties bearing the same label may differ significantly in terms of their general ideological orientations, policy proposals, and competitive status in particular regions. Thus, a federal system, especially a decentralized one, may foster interlevel variations in the linkage and mobilization functions of parties and, relatedly, different contexts of group-based socialization and party choices. Consonant with these possibilities, the social-psychological theory suggests that variations in national and subnational party systems reflect and reinforce cross-level differences in socialization processes that affect the ties between social groups and political parties at the two levels of government. A rational-choice argument, however, contends that the choices offered by federal and subnational party systems encourage individuals to adopt different party identifications at the national and subnational levels, or to develop an identification at only one level.

The Canadian case is an ideal one for investigating the argument that citizens may acquire attachments to different parties in a federal system. Canadian federalism was established originally with a strong national government and specific subnational powers to accommodate deep, territorially related divisions in Canadian society. Over time, however, the subnational units have assumed major responsibilities and considerable salience (Jackson and Jackson 1990, ch. 6; Kornberg, Mishler and Clarke 1982). In addition, highly decentralized federalism and strong ethno-linguistic and regional cleavages have been reciprocally reinforcing and significant factors in the evolution of provincial party systems (Stevenson 1989). Federal-provincial differences in party systems, in turn, have contributed to the decentralization of Canadian federalism. As a result, differences between the national and subnational party systems have varied across the country, with the largest occurring in British Columbia and Quebec (Clarke, Kornberg and Stewart 1992). Canada thus is characterized by different arenas of political choice that are conducive to differentiated attitudes between both government levels. Indeed, some observers have suggested that many Canadians psychologically inhabit "two political worlds" (Blake 1985; Elkins and Simeon 1980).

In Canada, such differences in political attitudes have been exemplified by the willingness of a sizeable minority to identify with different parties at the two levels of the federal system (Blake 1982, 1985; Clarke et al. 1974, 1991; Clarke and Stewart 1987; Uslaner 1989, 1990; Martinez 1990). The potential for systemlevel variations in other attitudes, such as political efficacy or trust, also has begun to receive scholarly recognition (Lambert et al. 1986; Stewart et al. 1992). In other countries with federal systems, however, less attention has been paid to mapping individual-level patterns of party identification or other attitudes at different levels of government. In the United States, such sparse research initially found that strong similarities between dominant parties in the national and regional or state party systems encouraged many Americans to identify with the same party at both levels (Converse 1966; Jennings and Niemi 1966). More recent investi- 
gations, however, have suggested that processes of political change, including stronger roles for state governments and growing differences in issue environments, have increased Americans' propensities to identify with different parties in national and state politics (Hadley 1985; Niemi, Wright and Powell 1987).

Although some scholars have attributed American-Canadian differences in party identification to cross-national dissimilarities in political institutions (i.e., the numbers of parties, the forms of government) and political culture (Uslaner 1990), or question-wording discrepancies between the surveys conducted in both countries (Johnston 1992), we contend that the greater decentralization of Canada's federal system establishes this country's uniqueness with respect to the phenomenon of partisan inconsistency. We consider this possibility by comparing the patterns of split-level identification in the United States and Canada. We then examine cross-temporal and cross-regional differences in the latter. The dynamism of split-level identification over time and across regions suggests the importance of short-term forces, net of other factors operating in the political arena. Finally, we investigate the effects of party identification at both levels of government on issue and leader evaluations as well as electoral choice.

\section{Partisan Inconsistency in Canada}

This paper focuses on three groups -- people who identified with the same party at both levels of government (consistent identifiers), those who identified with different parties (inconsistent or split identifiers), and individuals who possessed an identification at either the national or subnational level, but not both (single-level identifiers). These groups are constructed using national data from the NES Pilot and state surveys conducted in New Jersey, Louisiana, and Florida in 1987. ${ }^{1}$ In Canada, party identifications at the national and provincial levels have been measured since the first national election study in 1965 . We employ parallel sets of questions about party identification at the two levels that were administered in several national surveys over the $1974-90$ period. $^{2}$

Figure 1 reports the data from the four American studies in 1987 and the 1988 pre-election wave of the Political Support in Canada Study. In the 1987 NES pilot, fully 86 percent of the respondents identified with the same party in national and state politics. Consistent identifiers accounted for slightly less than three-quarters of the Florida sample and more than three-quarters of the interviewees in Louisiana and New Jersey. All four studies were markedly similar with respect to the low frequencies of individuals who identified with different parties at both levels -- in each survey, inconsistent identifiers were less than 5 percent of the electorate. The state polls also show a somewhat greater propensity to identify with a party at only one level as compared with the NES results (7-9 percent versus 3 percent). Moreover, two state polls -- New Jersey and Florida -- reveal larger numbers of persons who did not identify with any party compared to Louisiana or the NES. The 1988 Canadian data reveal several significant contrasts with their 1987 American counterparts. In Canada, a central property of partisanship involves a greater 
tendency not to identify with the same party at both levels of government. Threefifths of the Canadian respondents identified with the same party, but slightly over one-quarter identified with different parties in federal and provincial politics. The percentages of those interviewed who claimed to identify with a party at only one level, or not to identify at all, were 8 percent and 6 percent, respectively.

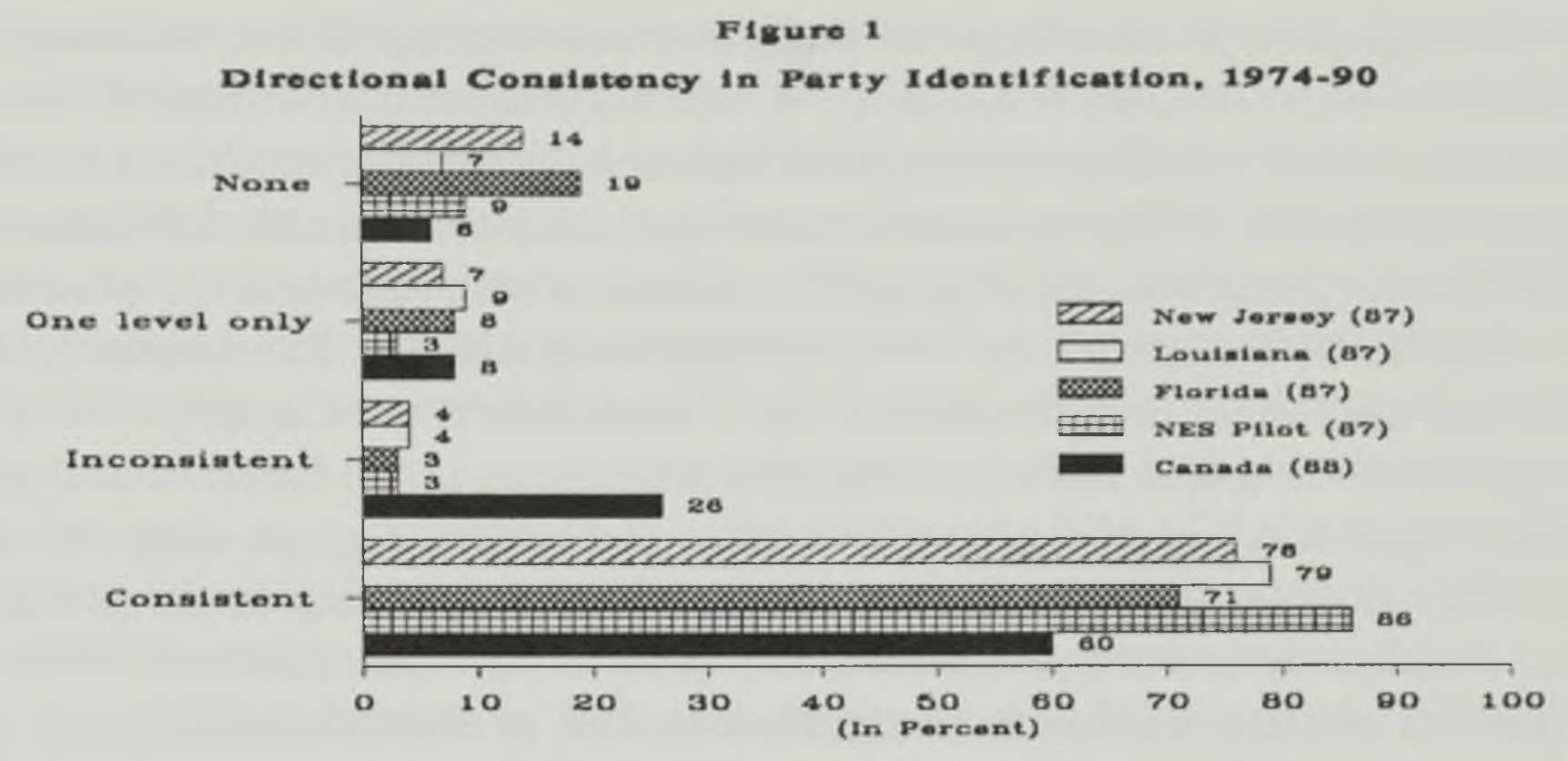

Also noteworthy is the finding that sizable groups of inconsistent partisans are present in all of the 1974-90 Canadian surveys (Figure 2). Substantial splitlevel identification is not confined to surveys conducted in non-election years as opposed to election years when parties presumably are most active in performing the tasks of political mobilization. Rather, the general over-time pattern is one in which the numbers of consistent identifiers have been declining gradually while inconsistent identifiers have accounted for a larger portion of the Canadian electorate. Indeed, the data for the 1974-90 period show that the percentages of consistent identifiers, while averaging 60 percent of the electorate, have ranged from a high of 64 percent in 1974 to a low of 57 percent in 1990. The mean number of inconsistent partisans was 23 percent and fluctuated between 17 percent in 1974 and 26 percent in 1988 and 1990. The percentages of single identifiers and nonidentifiers have shown less movement over time.

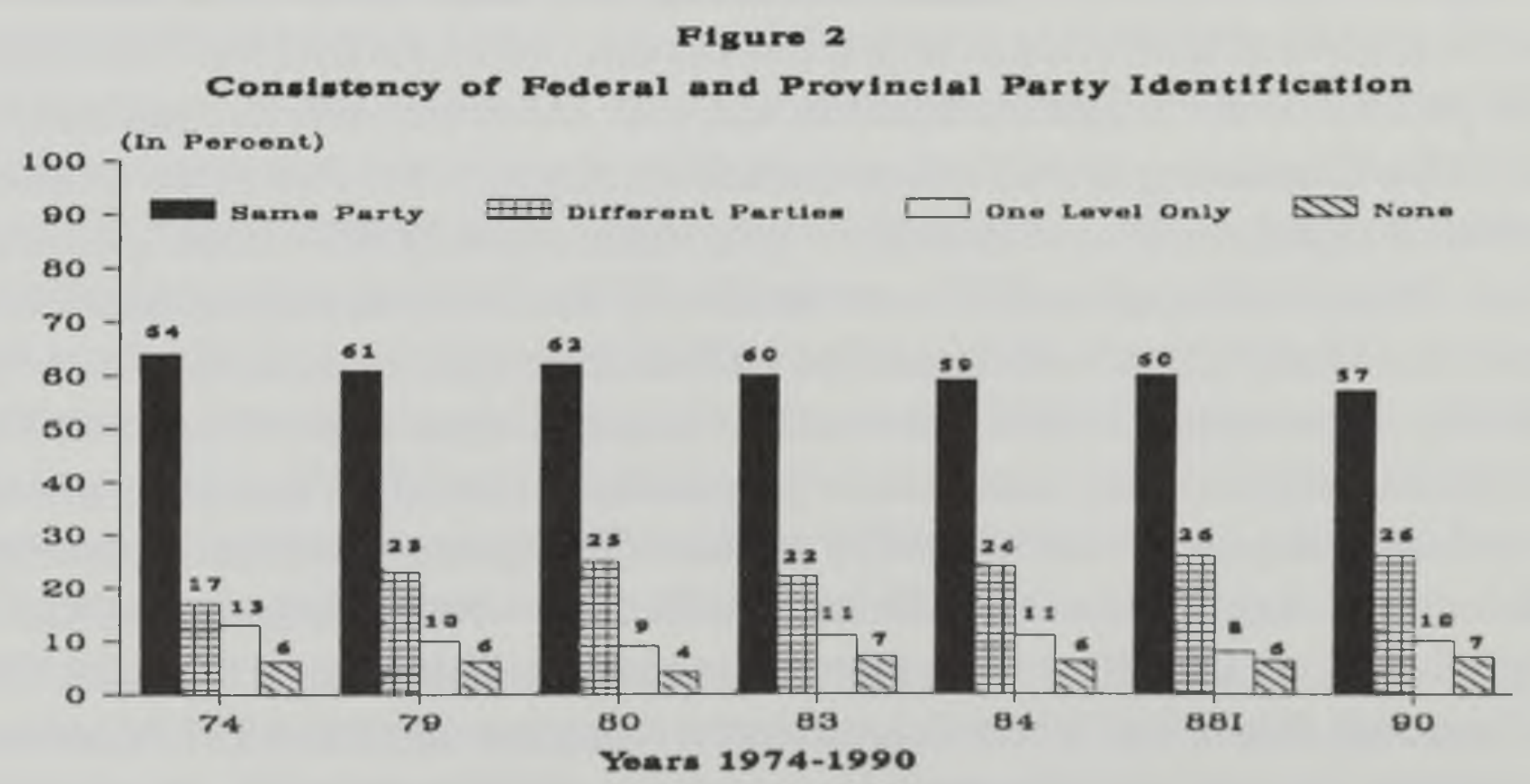


Data gathered over the 1974-90 period further demonstrate that neither the phenomenon nor the dynamism of partisan inconsistency has been confined to regions of the country with highly disjunctive federal and provincial party systems (Figure 3). In Quebec and British Columbia, where very different arrangements of political parties and inter-party competition have existed at the federal and provincial levels, the percentages of inconsistent identifiers have been higher than in other regions. In Quebec, these percentages increased substantially -- from 22.3 percent in 1974 to 49.2 percent in 1988 -- and then decreased (to 44.7 percent) in 1990. In British Columbia, the numbers of persons who identified with different parties at both levels rose between 1974 (32.8 percent) and 1980 (54.3 percent) and then began to fall during the next ten years, until reaching 40.5 percent. Fewer split identifiers have resided in the Prairie provinces, where federal and provincial party systems have tended to differ over time and the Reform Party entered the political scene in 1987. In this region, the percentages of inconsistent partisans fell from 21.3 percent in 1974 to 11.5 percent in 1983 and then climbed to 17.1 percent in 1988 and 24.4 percent in 1990 . In Ontario, where the major national parties also have been important provincial actors and a NDP government was formed for the first time in 1990, the numbers of inconsistent identifiers rose gradually between 1974 (9.9 percent) and 1980 (17.1 percent), and then remained relatively unchanged until declining from 1984 (16.5 percent) to 1988 and 1990 (11.9 percent). Only in the Atlantic region, where federal and provincial party systems have been quite similar, have the percentages of inconsistent identifiers remained relatively low over time.

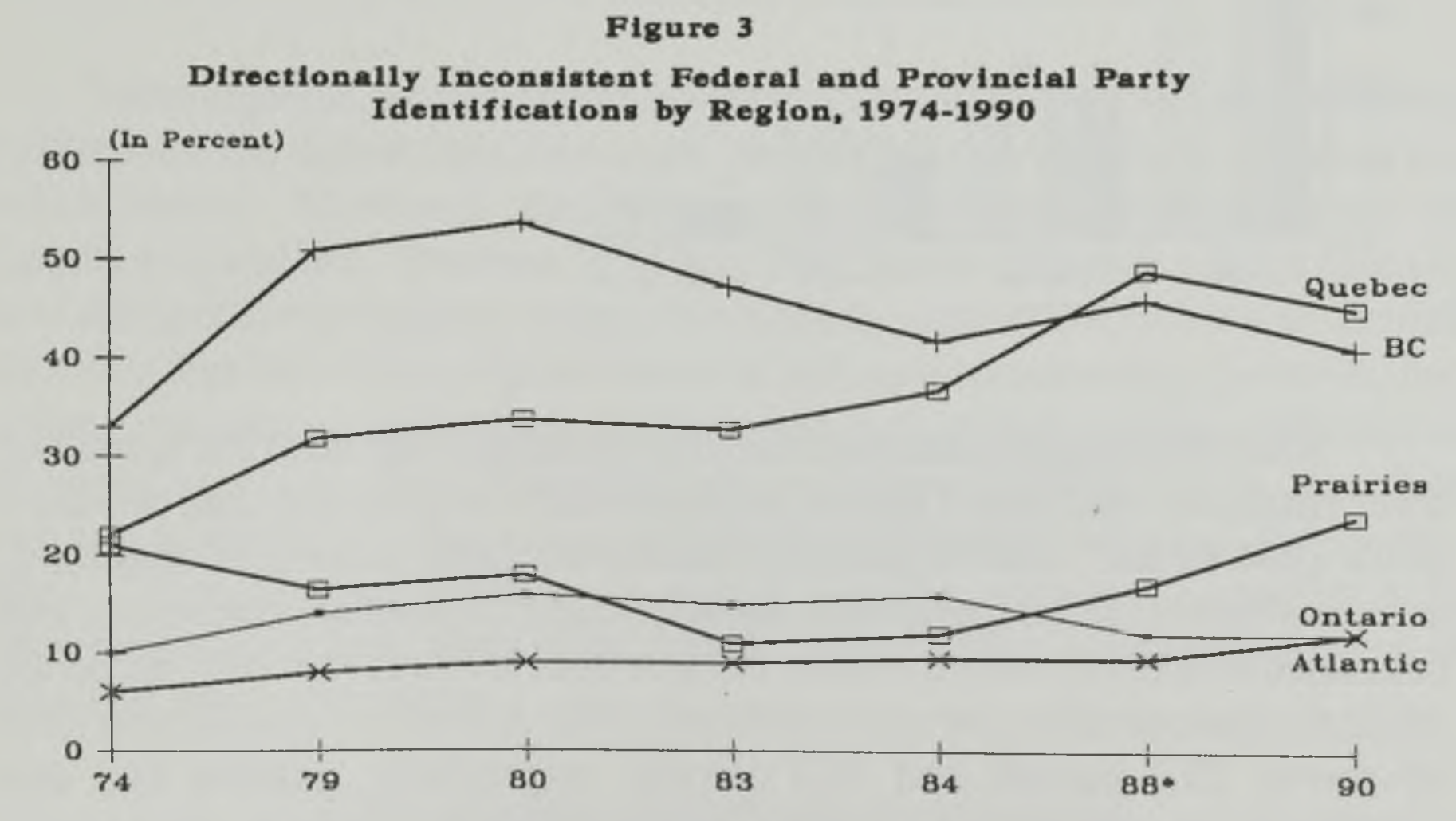

- prelection survey

Conventional wisdom concerning the dynamism of partisan attitudes, however, suggests that aggregate-level trends may not be duplicated in individuallevel patterns, and that accurate measurement of the latter requires the use of panel data. Our focus on the 1984-88 and 1988-90 panelists in the Political Support in 
Canada Study reveals sizeable movements in individuals' identifications with political parties at each level of government (Figure 4). At the federal level, slightly les than two-thirds of the respondents maintained directionally stable partisan attachments, and only one in twenty was a stable non-identifier in either 1984-1988 or 1988-90. Another one-fifth, however, switched their identifications and slightly over 10 percent either acquired or abandoned an identification with a national party in each period. The data on provincial party identification tell a similar story -- in sum, nearly 30 percent changed parties or found/lost an identification at the provincial level between 1984 and 1988, as well as 1988 and 1990.

\section{Figure 4}

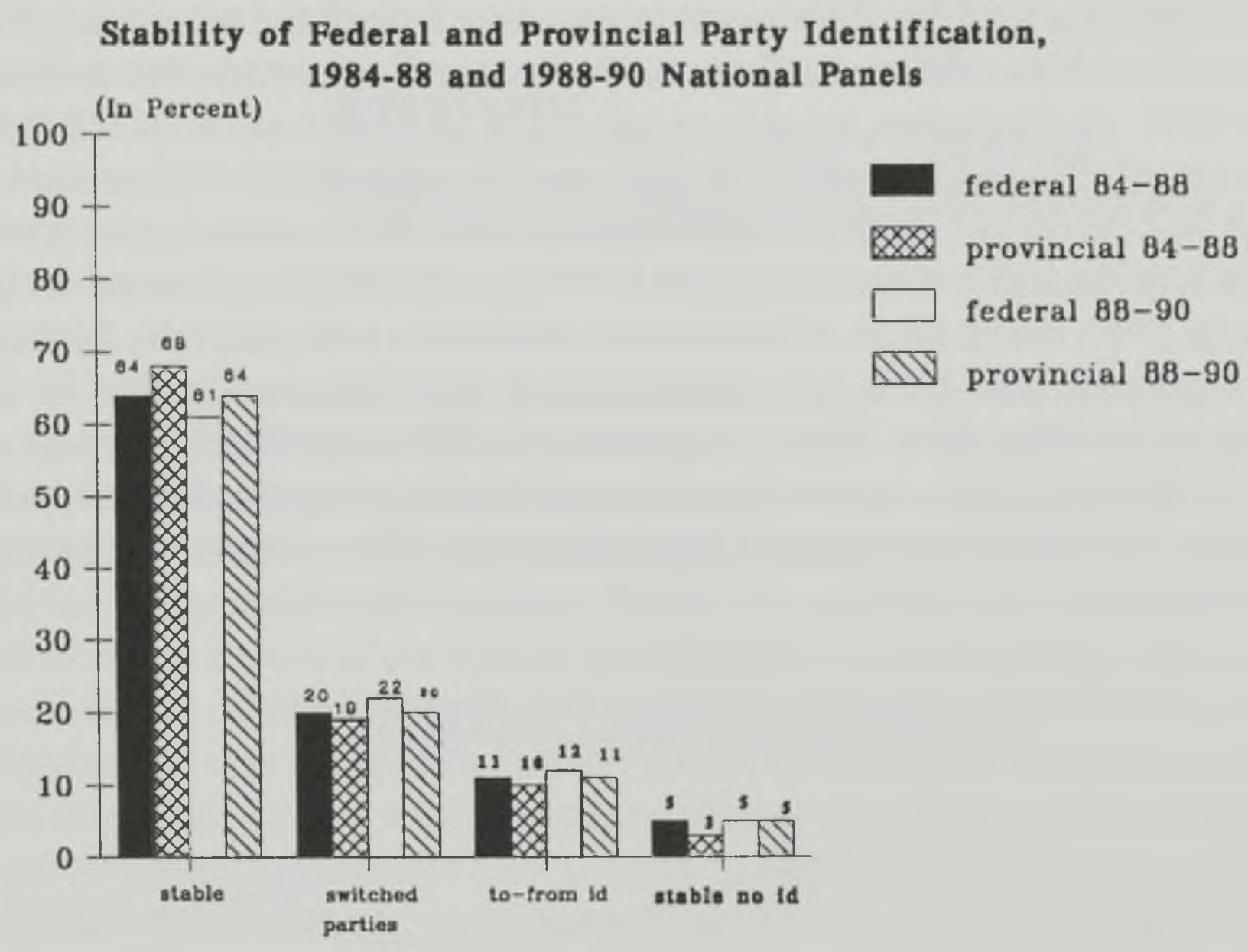

These data suggest that partisan (in)consistency will manifest individuallevel instability. As Table 1 shows, this is the case -- slightly less than two-thirds of the 1984-88 and 1988-90 panelists manifested stable patterns of consistency or inconsistency. More specifically, approximately 50 percent of the respondents continued to identify with the same party at both levels in the 1984-88 period, while 41.8 percent did so between 1988 and 1990. Across the 1984-88 and 198890 waves, 13.6 percent and 16.2 percent, respectively, reported that their identifications with different parties at the federal and provincial levels remained unchanged. Much smaller percentages reported stable partisanship at only one level or stable non-identification at both levels of the federal system. In contrast, slightly more than one-third of the electorate reported a change at both levels between 1984 and 1988, as well 1988 and 1990. This group includes 10 percent 
who moved from consistent to inconsistent identifications and another 8 percent who changed in the opposite direction. The remainder manifested other patterns of partisan variation.

Table 1. Stability of Consistenct of Federal and Provincial PartyIdentification, 1984-1988 and 1988-90 National Panels

\section{Stable Patterns}

Same Party Both Levels

Different Party

Federal Party Only

Provincial Party Only

No ldentification

Total

Unstable Patterns

Same Party $\rightarrow$ Different Party

Different Party $\rightarrow$ Same Party

Other Palterns

Total

Weighted $\mathrm{N}=$
$48.4 \%$

13.6

0.5

0.5

2.0

65.0

$10.7 \%$

8.3

$\underline{16.0}$

35.0

738
$41.8 \%$

16.2

0.8

1.5

2.4

62.7

$10.4 \%$

7.8

19.1

37.3

1062

Taken together, the data presented above suggest that partisan inconsistency is a phenomenon that distinguishes party identification in Canada from that in the United States. Moreover, this phenomenon is a long-standing feature of Canadia political life. Between 1974 and 1990, levels of partisan inconsistency have differed across regions, being considerably greater in Quebec and British Columbia than elsewhere. The incidence of split-level partisanship, however, has not been constant within regions, and the magnitude of inter-regional differences has varied over time. Both federal and provincial party identifications, as well as partisan inconsistency, also have manifested considerable individual-level instability. These findings combine to suggest that the tendency to identify with different parties at both levels of the federal system reflects a complex mixture of long- and short-term forces.

\section{The Correlates of Partisan Inconsistency}

Most explanations of the sources of federal-provincial differences in party identification (e.g., Blake 1985; Martinez 1990; Uslaner 1990; but see Bowler, 1990) have echoed conventional wisdom about the significance of long-term forces reflecting subnational cleavages in Canadian political culture (e.g., Bell and 
Tepperman 1979; Elkins and Simeon 1980; Schwartz 1974; Simeon and Elkins 1974; Wilson 1974). Although recent research indicates that some claims regarding large regional/ethnic differences in public political orientations are unwarranted (Clarke, Pammett and Stewart 1992), federal and provincial party systems in the several provinces have varied widely. Patterns of party competition in federal and provincial politics differ across the provinces and, in British Columbia and Quebec, parties that are highly competitive at one level of government are much weaker or nonexistent at the other. These party-system differences undoubtedly both reflect and reinforce the regional variations in partisan inconsistency observed in the 1974-90 survey data.

Previous studies have argued that these complex patterns of support for federal and provincial parties are products of regional differences in public orientations toward the national political regime and community. Perhaps most obviously, the strength of the separatist Parti Québécois in Quebec provincial politics reflects the disaffection that many residents of this province feel toward the national community and their accompanying desire for a sovereign Quebec (e.g., Clarke 1983; McRoberts 1988). Since the late 1960s, the $P Q$ has been the principal political vehicle for the expression of these sentiments, but it is not the first party to articulate Québécois nationalist aspirations. In earlier eras, other "Quebec-only" parties, such as the Bloc Populaire and the Union Nationale, did so and, since 1988, the Bloc Québécois (a group of dissident federal Progressive Conservative MPs) have done so as well.

Similarly, it is argued that the weakness of the federal Liberal Party during much of the post-World War II period and the long history of "third-party" protest movements in the Western provinces (the Progressives in the 1920s, the CCF and Social Credit in the 1930s, Reform since the late 1980s) reflect their inhabitants' unhappiness with the costs and benefits conferred by the federal system and the inadequate representation of Western interests by the oldline federal parties (the Liberals and Progressive Conservatives) in Ottawa (Irving 1959; Lipset 1968; Macpherson1953; Stevenson 1989; Young 1969). These parties, operating within the institutional confines of a Westminster-model parliamentary system and a single-member plurality electoral system, have adopted policies that benefit the more populous provinces of central Canada (Ontario and Quebec), while working continuing economic hardships on the West.

The discontents of Quebecers, Westerners, and other Canadians with their political parties may be longstanding, but they are not static. Rather, unhappiness historically has waxed and waned in response to a changing mix of economic and political events and conditions. Some periods of especially profound discontent, such as the great depression of the 1930s or the constitutional crisis that began in the 1970s, have been quite long-lived. It might be hypothesized that these protracted episodes of displeasure have had important socialization effects on persons entering the electorate when they were occurring. If so, patterns of federal and provincial party identifications and, hence, levels of partisan inconsistency might be expected to vary across age cohorts. 
Long-term forces, such as those associated with regional political cultures and inter-generational differences in political socialization, cannot be the whole story. Rather, the dynamism in support for both federal and provincial parties suggests that partisan inconsistency has other sources. At any point in time, federal and provincial partisanships are partially driven by short-term forces, many of which are generated by events and conditions specific to particular political contexts (e.g. Bowler 1990; Clarke and Stewart 1985, 1987). Individual-level instability in partisan inconsistency reflects the operation of these factors.

Here, we analyze the impact of a mix of long- and short-term forces on partisan inconsistency using data gathered in the 1988 Political Support in Canada Survey. The possible effects of regime-and community-level orientations are assessed with measures of perceptions of the costs and benefits of the federal system, and the strength of orientation towards the national versus the provincial political community. ${ }^{3}$ Regional/ethnic effects are captured using five dummy variables, with Ontario residence as the reference category. Inter-generational socialization effects are assessed using five age cohort dummy variables corresponding to "political eras" when members of the electorate reached the age of majority. Circa 1988, the age groups were: 18-25 (Mulroney era), 26-43 (Trudeau era), 44-55 (Diefenbaker-Pearson era), 56-69 (post-World War II era), 70 and over (pre-World War II era).

The partisan inconsistency models include several other independent variables. A measure of support for the incumbent (Progressive Conservative) federal government and a summary measure of support for the three national federal parties (Liberals, Progressive Conservatives, NDP) are incorporated to investigate the hypothesis that partisan inconsistency is partially a product of authority-level attitudes. ${ }^{4}$ Given that support for provincial PC parties varies widely across the country and the party is effectively nonexistent in Quebec provincial politics, we expect that support for the federal PCs should be positively related to partisan inconsistency. In contrast, since disaffection with the federal parties historically has been a motivating force for the development of third-party movements in various provinces, we expect overall support for the three major federal parties (Liberals, PCs, NDP) as a group should be negatively related to partisan inconsistency. Since previous research (Clarke and Kornberg 1992) indicates that annual family income and gender are related to attitudes towards the federal political parties, these sociodemographic characteristics also are included in the models. ${ }^{5}$ Level of formal education and political interest are used to index exposure to miscellaneous short-term forces that, ceteris paribus, should enhance the likelihood of partisan inconsistency. ${ }^{6}$

The models employ two measures of partisan inconsistency as dependent variables. The first distinguishes between persons who identify with the same federal and provincial party and "split identifiers" who identify with different parties. The second measure separates persons who identify with the same federal and provincial party from those who are split identifiers or single-level identifiers. Since these variables are dichotomies, ${ }^{7}$ Probit is chosen for estimation purposes 
(Aldrich and Nelson 1984).

Several of the predictors behave as hypothesized. Support for the governing federal party, the Progressive Conservatives, is positively associated with partisan inconsistency defined either as split identification or split identification plus single-level identification. Also as expected, overall support for the three major federal parties is negatively associated with partisan inconsistency. Regime- and community-level orientations are relevant as well. Support for the national political community is negatively related to both measures of inconsistency, and perceptions that the federal system confers costs and benefits unfairly has a positive impact on the likelihood of being a split identifier.

Table 2. Probit Analyses of Directional Inconsistency in Party Identification, 1988 Pre-election Survey

\begin{tabular}{|c|c|c|c|c|c|}
\hline \multicolumn{2}{|c|}{ Predictor Variables } & \multicolumn{2}{|c|}{$\begin{array}{l}\text { Same Party v. Split } \\
\text { Party Identification }\end{array}$} & \multicolumn{2}{|c|}{$\begin{array}{l}\text { Same Party v. Split Party } \\
\text { and Single-Level Identification }\end{array}$} \\
\hline & & $b$ & $t$ & $b$ & $t$ \\
\hline \multirow[t]{4}{*}{ Age Cohort: } & $18-25$ & 0.32 & $1.97^{c}$ & 0.28 & $1.97^{\mathrm{c}}$ \\
\hline & $26-43$ & 0.36 & $2.46^{b}$ & 0.31 & $2.42^{b}$ \\
\hline & $44-55$ & 0.30 & $1.93^{c}$ & 0.24 & $1.71^{\mathrm{c}}$ \\
\hline & $56-69$ & 0.20 & 1.27 & 0.20 & 1.42 \\
\hline \multicolumn{2}{|l|}{ Education } & 0.06 & $1.77^{c}$ & 0.05 & $1.45^{\mathrm{d}}$ \\
\hline \multicolumn{2}{|l|}{ Gender } & -0.20 & $-2.81^{b}$ & -0.16 & $-2.37^{b}$ \\
\hline \multicolumn{2}{|c|}{ Income } & -0.03 & -1.24 & -0.03 & $-1.78^{c}$ \\
\hline \multicolumn{6}{|c|}{ Region/Ethnicity: } \\
\hline \multicolumn{2}{|c|}{ Atlantic } & -0.22 & $-1.52^{\mathrm{d}}$ & -0.26 & $-1.99^{c}$ \\
\hline \multicolumn{2}{|c|}{ Quebec-French } & 1.43 & $14.43^{2}$ & 1.33 & 14.79 \\
\hline \multicolumn{2}{|c|}{ Quebec-Non-French } & 0.50 & $2.07^{c}$ & 0.44 & $2.00^{c}$ \\
\hline \multicolumn{2}{|c|}{ Prairies } & 0.11 & 1.06 & 0.03 & 0.28 \\
\hline \multicolumn{2}{|c|}{ British Columbia } & 1.08 & $9.97^{\mathrm{c}}$ & 0.90 & $9.00^{2}$ \\
\hline \multicolumn{2}{|c|}{ Costs-Benefits of Federalism } & 0.09 & $1.95^{\mathrm{c}}$ & 0.05 & 1.23 \\
\hline \multicolumn{2}{|c|}{ Federal PC Government Support } & 0.01 & $4.73^{2}$ & 0.01 & $3.96^{=}$ \\
\hline \multicolumn{2}{|c|}{ Federal Parties Support } & -0.01 & $-2.04^{c}$ & -0.01 & $-2.74^{2}$ \\
\hline \multicolumn{2}{|c|}{ Political Community Orientation } & -0.10 & $-2.36^{b}$ & -0.12 & $-3.01^{*}$ \\
\hline \multicolumn{2}{|c|}{ Political Interest } & 0.09 & $1.60^{\mathrm{d}}$ & 0.05 & 0.97 \\
\hline \multicolumn{2}{|c|}{ Constant } & -1.59 & $-5.77^{d}$ & -0.91 & $-3.72^{2}$ \\
\hline \multirow{2}{*}{\multicolumn{2}{|c|}{$\begin{array}{l}\text { McKelvey } \mathrm{R}^{2}= \\
\% \text { Correctly Classified }\end{array}$}} & \multicolumn{2}{|c|}{.34} & \multicolumn{2}{|c|}{.31} \\
\hline & & \multicolumn{2}{|c|}{78.6} & \multicolumn{2}{|c|}{78.5} \\
\hline \multicolumn{2}{|c|}{ Weighted $\mathrm{N}=$} & \multicolumn{2}{|c|}{1754} & \multicolumn{2}{|c|}{1927} \\
\hline
\end{tabular}

Regarding other predictors, the 18-25, 26-43, and 44-55 age groups all are significantly more likely to be inconsistent partisans than were older persons. Since these groups are ones that reached the age of majority during the past quarter 
century when disaffection with the federal parties has increased significantly (Clarke and Kornberg 1993), the results are consistent with the hypothesis of generationally related socialization differences. In this regard, the largest coefficients are for the Trudeau-era cohort (26-43 years of age) -- persons who entered the electorate during a period when federal-provincial conflicts were especially acrimonious.

Gender, income, and education also have significant effects, with the signs on their coefficients indicating that women, persons in lower income categories, and those with higher levels of formal education are more likely to be inconsistent partisans. Since previous analyses have shown that women and those with lower incomes tended to support federal parties other than the PCs in 1988 (Clarke and Kornberg 1992), the gender and income relationships provide additional evidence that feelings about incumbent parties have significant effects on partisan inconsistency. The significant, positive education coefficients in the two analyses and the significant, positive political interest coefficient in the same party v. split party identification model are consonant with the hypothesis that exposure to various short-term forces operating in the political system at particular points in time enhances the likelihood of partisan inconsistency.

Most of the region/ethnicity dummy variables are significant as well. Echoing the descriptive data presented earlier, the incidence of partisan inconsistency is positively associated with residence in Quebec or British Columbia, and negatively related to residence in the Atlantic provinces. The strength of these relationships can be appreciated by the results of additional analyses in which the region/ethnicity variables are the only predictors in the models. These analyses show that the estimated (McKelvey) $\mathrm{R}^{2}$ scores are .29 for the same party v. split party identification and .26 for the same party v. split party and single-level party identification models, respectively. These values indicate that the region/ethnicity dummies, by themselves, can account for nearly 85 percent of the variance explained by the full models.

In sum, the analyses buttress the argument that a variety of long- and shortterm forces influences partisan inconsistency. Support for political parties at both levels of government varies over time and, as it does, levels and patterns of partisanship do so as well. However, these short-term dynamics occur within regionally differentiated party systems and politocultural contexts that have strong impacts on specific patterns of federal and provincial party identifications in various parts of the country. As several observers (e.g., Blake 1985; Uslaner 1990) have argued, the inertial properties of these contexts do much to account for the continuing presence of high levels of partisan inconsistency in Canada.

\section{Does Inconsistency Matter?}

Partisan inconsistency clearly is a persistent feature of Canadian political psychology. Still unanswered, however, is the question of whether inconsistent 
party identifications influence Canadians' political attitudes and behavior. As argued above, both traditional social-psychological and revisionist rationalchoice theories of party identification suggest that such effects should occur. According to the former theory, party identification is an affective group attachment that has direct effects on the vote, as well as indirect ones generated by its influence on how voters perceive and evaluate party leaders and salient campaign issues (Campbell et al. 1960, ch. 6). One would anticipate that consistent party identifications reinforce these "perceptual screening" effects, whereas inconsistent identifications create psychological cross-pressures that weaken or obviate them. According to the latter theory, party identification is a cognitive device that provides a cost-effective means of summarizing present and past information relevant to the vote decision. As a cumulatively updated "running tally" of party, leader, and candidate performance evaluations, ceteris paribus, party identification will have a larger value for persons who identify with the same party than for those who identify with different parties at both levels of government or identify with a party at only one level.

These predictions notwithstanding, some analyses of Canadian political behavior argue that such effects should not occur (e.g., Blake 1985; Elkins and Simeon 1980). These arguments assume that federal and provincial politics are largely divorced or even hermetically sealed from one another in the voters' minds. Since Canadians effectively inhabit separate federal and provincial "political worlds," party identification and other political attitudes, beliefs, and opinions that concern one level of government do not influence those involving the other level.

We investigate these rival hypotheses using the 1984-88 panel data gathered in the Political Support in Canada project. Our dependent variables are perceptions of the issue that dominated the 1988 federal election campaign, the proposed free trade agreement (FTA) between Canada and the United States (Clarke and Kornberg 1992), ${ }^{8}$ feelings about the leaders of the three major federal parties, and voting behavior in the 1988 election. Several predictor variables are used in the models. Since previous studies have established that party identification in Canada is endogenous to leader images and issue perceptions/evaluations (e.g., Archer 1987; Bowler 1990; Clarke and Stewart 1985, 1987; see also Franklin 1992), we measure federal and provincial party identification using data gathered in the 1984 wave of the panel. ${ }^{9}$ Other predictors include summary indices of evaluations of governmental effectiveness and equity/fairness, and various sociodemographic characteristics (age, education, gender, income, region/ethnicity). ${ }^{10}$

We first consider the impact of federal and provincial party identifications on perceived problems that might ensue if Canada was to implement the free trade agreement. ${ }^{11}$ We hypothesize that federal and provincial Conservative identifiers should be less likely to perceive problems with the FTA than other party identifiers and nonidentifiers. Persons who judge that the incumbent Conservative federal government has performed effectively and that the government operates equitably and fairly also should be more willing to accept Conservative arguments that the 
proposed free trade agreement will not pose problems. As for the sociodemographic variables, we anticipate that residents of Quebec and the Western regions (the Prairies, British Columbia) should be less likely to judge the FTA negatively than persons living in Ontario (Canada's industrial heartland -- the area most likely to experience negative effects of liberalized trade with the United States). Similarly, lower income Canadians, many of whom are employed in blue collar jobs that might be put at risk by the FTA, should be more likely to perceive problems with the agreement.

A multiple regression analysis yields results consistent with these hypotheses. Federal and provincial party identifications have significant effects on the number of perceived problems with free trade (Table 3 ). As anticipated, the signs on the coefficients for these variables are negative, indicating that federal and provincial PC identifiers are less likely to see problems with the FTA. Also as expected, persons making positive government effectiveness and equity/fairness judgments are less likely to perceive the impact of the FTA negatively, as are persons in higher income categories. Finally, Quebec-French and residents of the Prairies and British Columbia are less likely to see problems with free trade than are Ontarians.

Table 3. Regression Analysis of Perceived Problems with Free Trade, 1984-1988 National Panel Survey

\begin{tabular}{|c|c|c|c|}
\hline Predictor Variables & $b$ & $B$ & $t$ \\
\hline Age & -0.66 & -.02 & -0.00 \\
\hline Education & 0.01 & .00 & 0.09 \\
\hline Gender & 0.09 & .02 & 0.62 \\
\hline Income & -0.16 & -.11 & $-2.71^{b}$ \\
\hline Region/Ethnicity: Atlantic & -0.08 & -.01 & -0.31 \\
\hline Quebec-French & -1.42 & -.30 & $-7.00^{2}$ \\
\hline Region/Ethnicity: & -0.75 & -.05 & $-1.4 l^{d}$ \\
\hline Prairies & -0.74 & -.14 & $-3.70^{a}$ \\
\hline British Columbia & -0.82 & -.14 & $-3.43^{2}$ \\
\hline Federal Party Identification, 1984 & -0.28 & -.29 & $-6.41^{*}$ \\
\hline Provincial Party Identification, 1984 & -0.10 & -.10 & $-2.04^{c}$ \\
\hline Government Performance Evaluations & -0.07 & -.10 & $-2.50^{b}$ \\
\hline Equity/Fairness Evaluations & -0.17 & -.17 & $-4.44^{2}$ \\
\hline Constant & 5.52 & - & $11.26 \mathrm{a}$ \\
\hline Adjusted $\mathrm{R}^{2}=$ & & .27 & \\
\hline \multicolumn{4}{|l|}{ Weighted N = 629} \\
\hline \multicolumn{4}{|c|}{$=\mathrm{p} \leq .001 ;{ }^{b}-\mathrm{p} \leq .01 ;{ }^{c}-\mathrm{p} \leq .05 ; \mathrm{d}-\mathrm{p} \leq .10 ;$ one-tailed test } \\
\hline
\end{tabular}

We next consider affective feelings about the three federal party leaders -Prime Minister Brian Mulroney (Progressive Conservative), and opposition 
proposed free trade agreement will not pose problems. As for the sociodemographic variables, we anticipate that residents of Quebec and the Western regions (the Prairies, British Columbia) should be less likely to judge the FTA negatively than persons living in Ontario (Canada's industrial heartland -- the area most likely to experience negative effects of liberalized trade with the United States). Similarly, lower income Canadians, many of whom are employed in blue collar jobs that might be put at risk by the FTA, should be more likely to perceive problems with the agreement.

A multiple regression analysis yields results consistent with these hypotheses. Federal and provincial party identifications have significant effects on the number of perceived problems with free trade (Table 3). As anticipated, the signs on the coefficients for these variables are negative, indicating that federal and provincial PC identifiers are less likely to see problems with the FTA. Also as expected, persons making positive government effectiveness and equity/faimess judgments are less likely to perceive the impact of the FTA negatively, as are persons in higher income categories. Finally, Quebec-French and residents of the Prairies and British Columbia are less likely to see problems with free trade than are Ontarians.

Table 3. Regression Analysis of Perceived Problems with Free Trade, 1984-1988 National Panel Survey

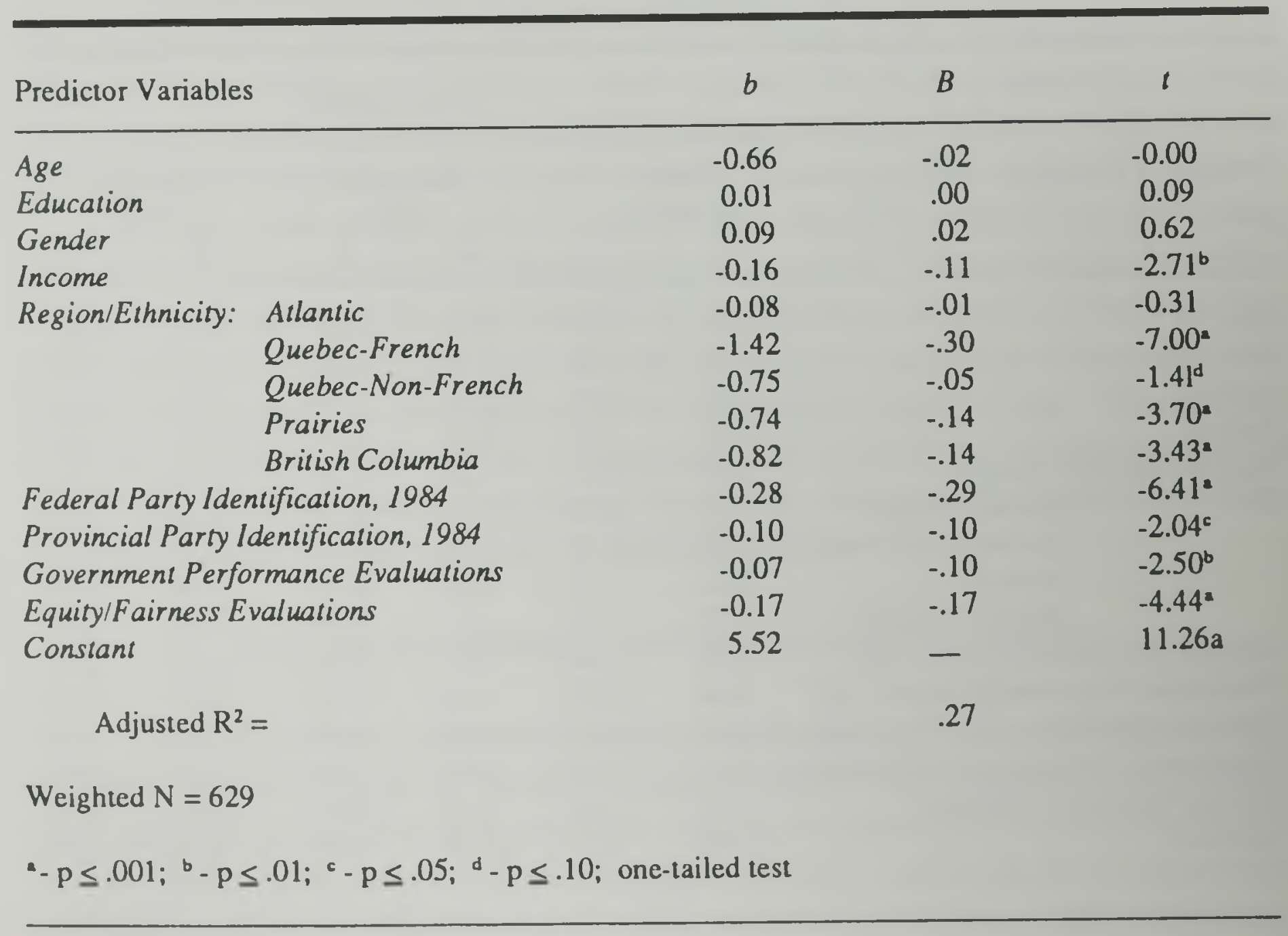

We next consider affective feelings about the three federal party leaders -Prime Minister Brian Mulroney (Progressive Conservative), and opposition 
leaders John Turner (Liberal) and Ed Broadbent (NDP). ${ }^{12}$ The party leader affect models are similar to those just discussed, with the exception that the number of perceived problems with the FTA also is included as a predictor variable. These analyses indicate that, net of federal party identification and all other influences, provincial party identification has a significant and positive impact on feelings about two of the three leaders -- Prime Minister Mulroney, and NDP Leader Broadbent (Table 4). ${ }^{13}$ Also, controlling for provincial partisanship and other predictors, federal party identification has a significant positive effect on all three leaders' images. Since the two party identification variables were measured in 1984 , it is likely that other, more proximate, forces were at work as well. In this regard, all three leaders' images are strongly affected by perceptions of problems with the free trade agreement; i.e., as the number of perceived problems increases, affect for the prime minister decreases and that for the two opposition leaders increases. Government effectiveness and equity/fairness judgments have predictably positive influences on feelings about the prime minister. Although many of the sociodemographic variables are not significant, net of other considerations, Mulroney receives an expectedly enthusiastic reception by Francophone residents of his native province (Quebec), and Broadbent is viewed more warmly by Ontarians than persons living in the Western provinces.

Table 4. Regression Analysis of Federal Party Leader Affect, 1984-1988 National Panel Survey

\begin{tabular}{|c|c|c|c|c|c|c|}
\hline \multirow{3}{*}{ Predictor Variables } & \multicolumn{6}{|c|}{ Party Leader } \\
\hline & \multicolumn{2}{|c|}{$\begin{array}{l}\text { Tumer } \\
\text { (Liberal) }\end{array}$} & \multicolumn{2}{|c|}{$\begin{array}{l}\text { Mulroney } \\
\text { (PC) }\end{array}$} & \multicolumn{2}{|c|}{$\begin{array}{l}\text { Broadbent } \\
\text { (NDP) }\end{array}$} \\
\hline & $b$ & $t$ & $b$ & $t$ & $b$ & $t$ \\
\hline Age & 0.06 & 1.23 & 0.00 & 0.06 & 0.03 & 0.49 \\
\hline Education & 0.78 & 1.04 & -0.18 & -0.23 & 1.35 & $1.86^{\mathrm{c}}$ \\
\hline Gender & 1.41 & 0.90 & 2.54 & $1.53^{\mathrm{d}}$ & 2.39 & $1.55^{\mathrm{d}}$ \\
\hline Income & -0.78 & -1.21 & 0.48 & 0.70 & 0.29 & 0.45 \\
\hline Region/Ethnicity: Atlantic & 2.93 & 1.03 & 2.24 & 0.75 & -2.66 & -0.95 \\
\hline \multirow{4}{*}{$\begin{array}{l}\text { Quebec-French } \\
\text { Quebec-Non-French } \\
\text { Prairies } \\
\text { Bristish Columbia }\end{array}$} & 2.95 & $1.35^{\mathrm{d}}$ & 13.73 & $5.57^{2}$ & -0.56 & -0.26 \\
\hline & 7.54 & 1.25 & 4.18 & 0.67 & -15.19 & $2.63^{b}$ \\
\hline & 2.42 & 1.07 & 1.04 & 0.44 & -4.96 & $2.25^{c}$ \\
\hline & 3.23 & 1.26 & 4.17 & $1.47^{\mathrm{d}}$ & -6.54 & $2.56^{\mathrm{c}}$ \\
\hline Federal Party Identification, 1984 & 3.08 & $5.84^{2}$ & 1.37 & $2.58^{b}$ & 1.72 & $2.78^{b}$ \\
\hline Provincial Party Identification, 1984 & -0.26 & -0.47 & 1.20 & $2.11^{\mathrm{c}}$ & 2.91 & $4.32^{2}$ \\
\hline Perceived Problems with Free Trade & 3.47 & $8.15^{2}$ & -3.92 & $-8.28^{2}$ & 2.03 & $4.88^{2}$ \\
\hline Government Performance Evaluations & 0.63 & $1.98^{\mathrm{c}}$ & 1.04 & $3.08^{2}$ & -0.24 & -0.77 \\
\hline Equity/Fairness Evaluations & 0.12 & 0.28 & 1.93 & $4.34^{2}$ & -0.12 & -0.28 \\
\hline Constant & 25.90 & 4.29 & 52.76 & $8.35^{2}$ & 44.70 & $7.72^{2}$ \\
\hline $\begin{array}{l}\text { Adjusted } R^{2}= \\
\text { Weighted } N=629\end{array}$ & \multicolumn{2}{|c|}{.20} & \multicolumn{2}{|c|}{.33} & \multicolumn{2}{|c|}{.21} \\
\hline$-p \leq .001 ;^{b}-p \leq .01 ;^{c}-p \leq .05 ;^{d}-1$ & $.10 ; 0$ & iled tes & & & & \\
\hline
\end{tabular}


The preceding analyses suggest that both federal and provincial party identifications have indirect influences on voting behavior in the 1988 federal election via their effects on issue perceptions and party leader images. To determine if the two party identification variables also exert direct impacts on the vote, we analyze Conservative, Liberal and NDP voting. The vote models include federal and provincial party identification, the leader affect thermometers, the measure of perceived problems with free trade, the government effectiveness and equity/fairness indices, and the sociodemographic variables. Since the vote variables are dichotomies, ${ }^{14}$ Probit again is an appropriate estimation technique.

The results indicate that, although federal party identification directly influences voting for all three parties, provincial party identification has a significant direct impact $(t=2.48)$ only in the Liberal case (Table 5). Its effect on NDP voting is marginally significant $(t=1.32)$, but is clearly insignificant in the $\mathrm{PC}$ case $(\mathrm{t}=0.88)$. Other findings buttress the hypothesis of indirect party identification effects. Perceived problems with free trade operate as anticipated, reducing the likelihood of a Conservative vote and increasing that of a Liberal or a New Democratic Party vote. Party leader effects also are abundantly evident, with 8 of 9 coefficients being statistically significant. As expected, positive feelings about the PC leader enhance the probability of voting for his party and reduce the probabilities of casting a Liberal or NDP ballot. Positive feelings about the Liberal and NDP leaders acted in analogous ways, with the sole exception of the insignificant impact of feelings about Broadbent on Conservative voting. These effects operate in models which control for other potentially relevant predictors, including government effectiveness and equity/fairness evaluations as well as region/ethnicity and several other sociodemographic characteristics.

In sum, both federal and provincial party identification influenced voting behavior in the most recent $C$ anadian national election. The two party identifications directly affected the vote for two of the major parties, the Liberals and the NDP, and they indirectly affected the vote for all three parties by helping to shape party leader images and perceptions of the dominant campaign issue. The analyses thus are consistent with both social psychological and rational choice theories of party identification, and they challenge the popular argument that $C$ anadian voters psychologically inhabit separate "political worlds."

\section{Partisan Inconsistency in Comparative Perspective}

Since the concept of party identification first was advanced forty years ago (Belknap and Campbell 1952), the subject of voters' psychological attachments with political parties has been a central concern to students of electoral behavior in the United States and other western democracies. Although this concern has stimulated much research and controversy, surprisingly little is known about the extent and consequences of partisan inconsistency across different levels of government. A noteworthy exception to this tendency is Canada, where a series 
of national surveys has included questions about party identification at the federal and provincial levels.

Table 5. Probit Analyses of Voting in 1988 Federal Election, 1984-1988

National Panel Survey

\begin{tabular}{|c|c|c|c|c|c|c|}
\hline \multirow{3}{*}{ Predictor Variables } & \multicolumn{6}{|c|}{1988 Vote } \\
\hline & \multicolumn{2}{|c|}{ Liberal } & \multicolumn{2}{|c|}{ PC } & \multicolumn{2}{|c|}{ NDP } \\
\hline & $b$ & $t$ & $b$ & $t$ & $b$ & $t$ \\
\hline Age & 0.00 & 0.44 & 0.00 & 0.40 & -0.01 & -1.24 \\
\hline Education & -0.12 & $-1.58^{d}$ & -0.05 & -0.75 & 0.01 & 0.13 \\
\hline Gender & 0.29 & $1.87^{\mathrm{c}}$ & 0.04 & 0.27 & -0.24 & $-1.48^{\mathrm{d}}$ \\
\hline Income & 0.06 & 0.92 & 0.14 & $2.43^{b}$ & -0.19 & $2.76^{\mathrm{b}}$ \\
\hline Region/Ethnicity: Atlantic & 0.10 & 0.36 & 0.04 & 0.15 & -0.38 & -1.16 \\
\hline Quebec-French & -1.10 & $-4.72^{=}$ & 0.47 & $2.17^{c}$ & 0.55 & $2.56^{b}$ \\
\hline Quebec-Non-French & -0.19 & -0.42 & 0.25 & 0.51 & -0.06 & -0.09 \\
\hline Prairies & -0.79 & $-3.53^{=}$ & 0.18 & 0.82 & 0.22 & 0.93 \\
\hline Bristish Columbia & -0.75 & $-2.99=$ & -0.03 & -0.13 & 0.68 & $2.64^{b}$ \\
\hline Federal Party Identification, 1984 & 0.24 & $4.87^{\circledR}$ & 0.14 & $3.23^{2}$ & 0.26 & $4.67^{*}$ \\
\hline Provincial Party Identification, 1984 & 0.13 & $2.48^{\mathrm{b}}$ & 0.04 & 0.88 & 0.08 & $1.32^{\mathrm{d}}$ \\
\hline Party Leader Affect: Turner & 0.03 & $6.24^{2}$ & -0.02 & $-5.03^{2}$ & -0.01 & $-2.16^{c}$ \\
\hline Mulroney & -0.02 & $-4.25^{2}$ & 0.03 & $7.43^{2}$ & -0.01 & $-2.29^{c}$ \\
\hline Broadbent & -0.02 & $-4.39^{=}$ & -0.00 & -1.04 & 0.03 & $6.07^{\star}$ \\
\hline Perceived Problems With Free Trade & 0.21 & $4.49^{2}$ & -0.31 & $-7.11^{2}$ & 0.21 & $4.26^{2}$ \\
\hline Government Performance Evaluations & 0.00 & 0.09 & -0.01 & -0.45 & -0.02 & -0.51 \\
\hline Equity/Fairness Evaluations & -0.03 & -0.58 & 0.08 & $1.92^{\mathrm{c}}$ & -0.03 & -0.59 \\
\hline Constant & -1.01 & $-1.53^{\mathrm{d}}$ & -0.22 & -0.36 & -1.52 & $-2.19^{c}$ \\
\hline McKelvey $\mathrm{R}^{2}$ & & & & 4 & & \\
\hline Correctly Classified = & & & & 7 & & \\
\hline \multicolumn{7}{|l|}{ Weighted $N=629$} \\
\hline \multicolumn{7}{|c|}{$\mathrm{A}-\mathrm{p} \leq .001 ;{ }^{\mathrm{b}}-\mathrm{p} \leq .01 ;^{\mathrm{c}}-\mathrm{p} \leq .05 ;^{\mathrm{d}}-\mathrm{p} \leq .10 ;$ one-tailed test } \\
\hline
\end{tabular}

These surveys clearly indicate that partisan inconsistency is common in the Canadian electorate. On average, approximately one-third of those interviewed did not identify with the same federal and provincial parties, and from nearly onefifth to slightly over one-quarter identified with different ones. These national figures mask sizable regional differences, with the incidence of partisan inconsistency being much higher in British Columbia and Quebec than elsewhere. The persistence of these national and regional patterns, however, does not mean that partisan inconsistency is highly stable at the aggregate and individual levels. Rather, the cohort of inconsistent identifiers has changed markedly in Quebec, and, 
in British Columbia and the Prairies, it has fluctuated by smaller, but still noteworthy, amounts. Individual instability is evident as well, with national panel data revealing that approximately one-third of the electorate change the pattern of their federal and provincial party attachments over two- to four-year intervals.

Taken together, these findings suggest that partisan inconsistency in Canada has dynamic properties and is the product of a complex mix of long-and short-term forces. Empirical analyses indicate that, although region/ethnicity accounts for much of the explained variance in who is or is not an inconsistent partisan at a particular point in time, orientations toward the political community, regime, and authorities have significant influences as well. Some of these orientations tap durable regionally-related differences in attitudes toward the political system, but others, especially feelings about incumbent parties and their leaders, are highly mutable. As the latter change, they influence partisan inconsistency and the dynamics thereof by heightening the likelihood of partisan instability at either the federal or provincial levels.

Although both traditional social-psychological and revisionist rationalchoice conceptualizations of party identification suggest that partisan inconsistency is consequential, several commentators have argued the contrary, maintaining that Canadians effectively inhabit separate federal and provincial "political worlds." Party identification at one level of government thus is irrelevant to attitudes and behavior at the other level. Multivariate analyses of 1984-88 national panel data, however, show that both federal and provincial party identifications exert direct and indirect influences on electoral choice, affecting attitudes toward the dominant issue in the 1988 federal election, party leader images, and the vote itself.

The findings concerning the importance of federal and provincial party identifications in Canada suggest the significance of the extent and the consequences of partisan inconsistency in other polities with federal systems. As noted, in the United States, levels of inconsistency more closely approximating those in Canada were reported in a study of party identification in the South during Wallace's third-party presidential candidacy in 1968 (Hadley 1985). The findings from an analysis of the $1958 \mathrm{NES}$ and 1964 Ann Arbor data (Jennings and Niemi 1966), ${ }^{15}$ however, remain echoed with only slight exaggeration in more recent results for the late 1980s. In this regard, national- and state-level survey data gathered in 1987 show that levels of partisan inconsistency are much lower in the United States than in Canada, with the principal difference being that, unlike Canadians, less than one American voter in twenty identifies with different parties in national and state politics. Overall, it appears that partisan inconsistency in the United States exhibits some of the dynamism found in Canada, but normally is much less prevalent than in the latter country. Yet, partisan inconsistency, when it occurs, has a variety of effects on electoral choice in the United States (Jennings and Niemi 1966, 93-96). Similarly, Niemi, Wright and Powell (1987, 1098-99) find that inconsistent partisanship is related to levels of political participation 
among a nationwide sample of persons contributing $\$ 100$ to the 1972 presidential campaigns.

Insofar as we have been able to determine, Australia is the only other federal system where the possibility of partisan inconsistency has been investigated. Even here, the data are very sparse -- during the mid-1960s, only 8 percent of Australian voters had different national and state party identifications. The former was the preeminent determinant of political behavior (Aitkin 1977, 47).

These comparative findings, however, are hardly definitive. Systematic analyses clearly are needed to enhance understanding of the nature, causes, and consequences of variations in party identification at different levels of government in federal systems. In Canada, the high levels of partisan inconsistency may be, as some have argued, a sui generis product of powerful forces generated by subnational differences in political culture and a highly decentralized federal system. Partisan inconsistency at both the aggregate and individual levels, however, exhibits a dynamism that outpaces the ability of cultural or institutional change to account for it. Short-term forces clearly are at work. Are these forces unique to Canada? Is there something distinctive about the cultural-institutional matrix of Canadian politics that facilitates their operation? The answers to these questions should recognize that political cultures in other federal states hardly are monolithic or unchanging, and the degree of decentralization in federal systems varies both among countries, and within them over time. Cross-national comparative analyses will help to provide the answers to these questions and, in so doing, should enrich our knowledge of how varying political cultures and institutional contex ts affect the development and configuration of the psychological underpinnings of party systems in democratic polities. A quarter-century ago, Campbell and his colleagues (1966) identified the importance of such inquiry. Now is the time to proceed with it.

\section{NOTES}

${ }^{1}$ The questions measuring national party identification in the 1987 NES Pilot survey are: (a) "When it comes to national politics, do you usually think of yourself as a Democrat, a Republican, an independent, or what?;" (b) [If party named in (a)] "Would you call yourself a strong [party named] or a not very strong [party named]?;" (c) [If independent in (a)] "Do you think of yourself as closer to the Republican party or to the Democratic party?" The questions on state party identification start with "When it comes to state politics..." and otherwise are identical. In the Florida, Louisiana, and New Jersey surveys, the national-level questions begin: "Now think about the national government, when you think about elections for President, generally speaking. ..." The state-level questions begin, for example: "Now, let's think about politics at the state level here in Florida. When you think about elections for governor and the state legislature here in Florida, generally speaking...."

The 1987 NES Pilot data are available from the ICPSR Data Archive. The 1987 Florida data were gathered in the 1987 Florida Annual Policy Survey, Survey Research 
Center, Policy Sciences Program, Florida State University. The 1987 Louisiana data were gathered in the Louisiana Survey conducted by the Department of Rural Sociology, Louisiana State University. The 1987 New Jersey data are from the Eagleton Poll, Rutgers University. The authors are solely responsible for the analyses and interpretations of these data presented here.

${ }^{2}$ The questions used to measure federal party identification are: (a) "Thinking of federal politics, do you usually think of yourself as Liberal, Conservative, NDP, Social Credit, or what?;" (b) "How strongly [party named] do you feel; very strong, fairly strongly, or not very strongly?;" (c) [If "refused," "don't know," "independent," or "none" in (a)] "Still thinking of federal politics, do you generally think of yourself as being a little closer to one of the parties than to the others?;" (d) [If "yes"] "Which party is that?" All respondents supplying a party label to questions (a) or (c) are considered to have some degree of party identification. Persons declining to provide a party label in (a) but doing so in (c) are classified as "not very strong" identifiers. A parallel sequence of questions and procedures is used to measure provincial party identification.

The 1974, 1979, and 1980 Canadian survey data are from the Canadian National Election studies conducted by Harold Clarke, Jane Jenson, Lawrence LeDuc and Jon Pammett, and funded by the Canada Council and the Social Sciences and Humanities Council of Canada. The 1983, 1984, 1988, and 1990 data are from the Political Support in Canada Study conducted by Harold Clarke and Allan Komberg, and funded by the National Science Foundation (U.S.). For additional information on the several surveys and the data sets, see Clarke et al. (1979, Appendices A, B); Kornberg and Clarke (1992, Appendix). The data are available from the ICPSR Data Archive, University of Michigan, Ann Arbor, Michigan. The authors are solely responsible for the analyses and interpretations of these data presented in this paper.

${ }^{3}$ To measure perceptions of the costs and benefits of federalism, respondents were asked: (a) "In your opinion, are some of the provinces bearing more than their fair share of the costs of governing Canada;" (b) "What about benefits? Are some provinces receiving more than their fair share?" "Yes" responses are scored 1; "no" and "don't know" responses, 0 . The cost-benefit index (range $0-2$ ) is created by summing the two variables. The national-provincial community orientation variable is created by subtracting the 100 point thermometer score variable measuring feelings about one's province of residence from a similar measure of feelings about $C$ anada. The resulting variable is collapsed into three categories: positive scores (Canada higher) $=2$, zero scores (Canada and province equal $)=1$, negative scores (province higher $)=0$.

${ }^{4}$ Support for the incumbent federal party, the Progressive Conservatives, is the mean score on 100-point thermometer variables measuring affect for the party and its leader, Prime Minister Brian Mulroney. Support for federal parties is the mean thermometer score for the Liberal, Progressive Conservative, and New Democratic parties.

${ }^{5}$ Annual family income has eight categories ranging from $\$ 10,000$ per year or less $=1$ to $\$ 70,000$ per year or more $=8$. Gender is: women $=1$, men $=0$.

${ }^{6}$ Level of formal education is elementary or less $=1$, some secondary $=2$, completed secondary or technical, community college $=3$, some university $=4$, completed university (B.A., B.Sc. or more) $=5$. Political interest is follows politics "very closely" $=3$, "somewhat closely" $=2$, "not much at all" $=1$.

${ }^{7}$ The partisan inconsistency var:ables are scoreci: inconsistent party identification = 1 ; consistent party identification $=0$.

${ }^{8}$ Survey data for federal elections conducted since 1974 indicate that the 1988 
contest was unusual in the extent to which a single issue was the focus of attention. Over $89 \%$ of our 1988 respondents stated that the free trade agreement was the most important issue in the election. No other issue was mentioned by as many as $2 \%$ of the respondents. See Clarke and Kornberg (1992: 142).

${ }^{9}$ The measures of federal and provincial party identification in this analysis are scored: very strong Conservative $=+3$, fairly strong Conservative $=+2$, weak or leaning Conservative $=+1$, nonidentifier $=0$, weak or leaning other party identifier $=-1$, fairly strong other party identifier $=-2$, very strong other party identifier $=-3$.

${ }^{10}$ The government effectiveness index (range $0-16$ ) is based on answers to a question inviting respondents to evaluate how well the federal government is performing in eight policy areas. In each case, the responses are scored "very well" $=+2$, "fairly well" $=+1$, "not very well" $=0$. The equity/fairness index (range 0-9) is based on "agree-disagree" responses to nine statements about the operation of the federal government and the larger political system. The several government effectiveness and equity/fairness items are presented in Kornberg and Clarke $(1992,86-88$, notes 13,15$)$. Note also that age is measured in years in the analyses of free trade problems, party leader affect, and vote.

${ }^{11}$ Respondents were asked if they "agreed" or "disagreed" with six statements concerning possible economic, political, and social consequences of the free trade agreement. The responses are recoded to yield an index of the number of perceived FTA problems (range 0-6). On the items and scoring procedure, see Clarke and Kornberg (1992: 152 , notes 10,12$)$.

${ }^{12}$ The party leader affect variables are 100 -point feeling thermometer scales.

${ }^{13}$ The scoring of the federal and provincial party identification variables is geared to which party leader is being considered. For example, in the analysis of feelings about PC Leader Mulroney, the party identification variables are scored as described in note 9 above. For the Liberal Leader Turner, an analogous scoring scheme is used, i.e., very strong Liberal $=+3$, fairly strong Liberal $=+2$, weak or leaning Liberal $=+1$, nonidentifier $=0$, weak or leaning other party identifier $=-1$, fairly strong other party identifier $=-2$, very strong other party identifier $=-3$. For the NDP Leader Broadbent, the scoring is very strong New Democrat $=+3$, etc.

${ }^{14}$ The dependent variable in the Conservative vote analysis is: voted $P C=1$, voted other party $=0$. The Liberal and NDP vote variables are constructed in a similar fashion.

${ }^{15}$ As Jennings and Niemi $(1966,100)$ note, partisan inconsistency also can arise as a result of the development of party identifications at the local, as well as the state (provincial) and national levels. Although "local party identification" has not been measured in the Canadian surveys, it likely is not very consequential since candidates for local office typically do not run under party labels.

\section{REFERENCES}

Aitkin, Don. 1977. Stability and Change in Australian Politics. New York: St. Martin's. Aldrich, John and Forrest Nelson. 1984. Linear Probability, Logit, and Probit Models. Beverly Hills: Sage Publications.

Archer, Keith. 1987. A Simultaneous Equation Model of Canadian Voting Behaviour. Canadian Journal of Political Science 20: 553-72. 
Beam, David R., Timothy J. Conlan and David B. Walker. 1983. Federalism: The Challenge of Conflicting Theories and Contemporary Practice. In Ada W. Finifter, ed., Political Science: The State of the Discipline. Washington: American Political Science Association.

Belknap, George and Angus Campbell. 1952. Political Party Identification and Attitudes toward Foreign Policy. Public Opinion Quarterly 15: 601-23.

Bell, David and Lorne Tepperman. 1979. The Roots of Disunity: A Look at Canadian Political Culture. Toronto: McClelland and Stewart.

Blake, Donald E. 1982.The Consistency of Inconsistency: Party Identification in Federal and Provincial Politics. Canadian Journal of Political Science 15: 691-710. , et al. 1985. Two Political Worlds: Parties and Voting in British Columbia. Vancouver: University of British Columbia Press.

Bowler, Shaun. 1990. Consistency and Inconsistency in Canadian Party Identifications: Towards an Institutional Approach. Electoral Studies 9: 133-46.

Campbell, Angus, Philip E. Converse, Warren E. Miller and Donald E. Stokes. 1960. The American Voter. New York: John Wiley \& Sons.

eds. 1966. Elections and the Political Order. New York: John Wiley \& Sons.

Clarke, Harold D. 1983. The Parti Québécois and Sources of Partisan Realignment in Contemporary Quebec. Journal of Politics 44: 64-85.

, Jane Jenson, Lawrence LeDuc and Jon H. Pammett. 1979. Political Choice in Canada. Toronto: McGraw-Hill Ryerson.

.1991. Absent Mandate: Interpreting Change in Canadian Elections. 2nd ed. Toronto: Gage.

Clarke, Harold D. and Allan Kornberg. 1992. Risky Business: Partisan Volatility and Electoral Choice in Canada, 1988. Electoral Studies 11: 138-56.

. 1993. Evaluations and Evolution: Public Attitudes Toward Canada's Federal Political Parties, 1965-1991. Canadian Journal of Political Science 26: forthcoming.

and Marianne C. Stewart. 1992. Canada. In Charles D. Ameringer, ed., Political Parties of The Americas, 1980s to 1990s. Westport: Greenwood Press.

Clarke, Harold D., Jon H. Pammett and Marianne C. Stewart. 1992. The Forest for the

Trees: Regions and Political Beliefs in Contemporary Canada. In Robert MacDermid, ed., The Canadian National Election Studies. Toronto: Oxford University Press.

Clarke, Harold D. and Marianne C. Stew art. 1985. Short-Term Forces and Partisan Change in Canada, 1974-80. Electoral Studies 4: 15-35.

1987. Partisan Inconsistency and Partisan Change in Federal States: The Case of Canada. American Journal of Political Science 31: 383-407.

Converse, Philip E. 1966. On the Possibility of Major Political Realignment in the South. In Angus Campbell et al., eds., Elections and the Political Order. New York: John Wiley \& Sons.

Elkins, David J. and Richard Simeon. 1980. Small Worlds: Provinces and Parties in Canadian Political Life. Toronto: Methuen.

Fiorina, Morris P. 1981. Retrospective Voting in American National Elections. New Haven: Yale University Press.

Franklin, Charles H. 1992. Measurement and the Dynamics of Party Identification. Political Behavior 14: 297-310. 
Hadley, Charles D. 1985. Dual Partisan Identification in the South. Journal of Politics 47: 254-69.

Irving, John A. 1959. The Social Credit Movement in Alberta. Toronto: University of Toronto Press.

Jackson, Robert J. and Doreen Jackson. 1990. Politics in Canada: Culture, Institutions, Behaviour and Public Policy, 2nd ed. Scarborough: Prentice-Hall.

Jennings, M. Kent and Richard G. Niemi. 1966. Party Identification at Multiple Levels of Government American Journal of Sociology 72: 86-101.

Johnston, Richard. 1992. Party Identification Measures in the Anglo-American Democracies: A National Survey Experiment. American Journal of Political Science 36: 542-59.

Komberg, Allan and Harold D. Clarke. 1992. Citizens and Community: Political Support in a Representative Democracy. New York: Cambridge University Press.

Komberg, Allan, William Mishler and Harold D. Clarke. 1982. Representative Democracy in The Canadian Provinces. Scarborough: Prentice-Hall.

Lambert, Ronald D., James E. Curtis, Steven D. Brown and Barry J. Kay. 1986. Effects of Identification with Governing Parties on Feelings of Political Efficacy and Trust. Canadian Journal of Political Science 19: 705-28.

Lipset, Seymour Martin. 1968. Agrarian Socialism: The Cooperative Commonwealth Federation in Saskatchewan. New York: Doubleday.

Macpherson, C.B. 1953. Democracy in Alberta: The Theory and Practice of a Quasi-Party System. Toronto: University of Toronto Press.

Martinez, Michael D. 1990. Partisan Reinforcement in Context and Cognition: Canadian Federal Partisanships, 1974-79. American Journal of Political Science 34: 82245.

McRoberts, Kenneth. 1988. Quebec: Social Change and Political Crisis, 3rd ed. Toronto:McClelland and Stewart.

Niemi, Richard G., Stephen Wright and Lynda W. Powell. 1987. Multiple Party Identifiers and the Measurement of Party Identification Journal of Politics 49: 1093-104.

Schwartz, Mildred A. 1974. Politics and Territory: The Sociology of Regional Persistence in Canada. Montreal: McGill-Queen's University Press.

Simeon, Richard and David J. Elkins. 1974. Regional Political Cultures in Canada Canadian Journal of Political Science 7: 397-437.

Stevenson, Garth. 1989. Unfulfilled Union: Canadian Federalism and National Unity, 3rd ed. Agincourt: Gage.

Stewart, Marianne C., Allan Komberg, Harold D. Clarke and Alan Acock. 1992. Arenas and Attitudes: A Note on Political Efficacy in a Federal System. Journal of Politics 54: 179-96.

Uslaner, Eric M. 1989. Multiple Party Identifiers in Canada: Participation and Affect. Journal of Politics 51: 993-1003. 1990. Splitting Image: Partisan Affiliations in Canada's 'Two Political Worlds.' American Journal of Political Science 34: 961-81.

Wilson, John. 1974. The Canadian Political Cultures: Towards a Redefinition of the Nature of the Canadian Political System. Canadian Journal of Political Science 7: 438-84.

Young, Walter D. 1969. The Anatomy of a Party: The National CCF 1932-1961. Toronto: University of Toronto Press. 